\title{
Juvenile glaucoma: Long-term development of ocular hypertension in children
}

\author{
Montero de Espinosa $\mathrm{M}^{1}$, Perea Pérez $\mathrm{R}^{2 *}$, Muñoz Schiattino $\mathrm{P}^{2}$, Infante Cossío $\mathrm{M}^{2}$ and Ponce $\mathrm{J}^{2}$ \\ ${ }^{1}$ University of Seville, Seville, Spain \\ ${ }^{2}$ Virgen Macarena University Hospital, Seville, Spain
}

\begin{abstract}
Aim: Study of the long-term development of children with treatment for ocular hypertension (OHT).

Purpose: IOP development, to detect risk factors and clinical features in children with OHT.

Method: A retrospective, descriptive and non-randomized study of 42 children treated for OHT, with a mean follow-up of 11.6 years.

Results: Most common family history: glaucoma (58\%) and myopia (23\%). The most frequent systemic pathological history was of airways disease, related in many instances to the use of corticosteroids. The most prevalent refractive error was found to be myopia (55\%). The most frequent reason for first time consultation was vision loss. The mean central corneal thickness found was $562 \mu \mathrm{m} \pm 41$. The diagnosis of childhood glaucoma using campimetry is difficult, since it relies on patient cooperation. In most cases, optic disc assessment, both ophthalmoscopically and using OCT, was not found to be reliable. The mean age of suspected OHT is 11 years old, usually considering abnormal pressure above $18 \mathrm{mmHg}$, and initiating treatment at $22 \mathrm{mmHg}$. The mean decrease through topical hypotensive medication was $4.7 \mathrm{mmHg}$, with no significant adverse effects registered. Forty-six percent of children abandoned medical treatment, after several years of control, upon verifying that IOP was normal.
\end{abstract}

Conclusions: Some children maintain high levels of IOP. Half of them will normalize their IOP around the age of 20 , but others will maintain OHT being adults. The response to medical treatment was sufficient in all the cases.

In the literature review, we did not find any series of children with OHT as extensive or over such a long period of time.

\section{Introduction}

Juvenile glaucoma refers to the onset of disease after the age of 3 (with an age limit for appearance of 18-35 years) and is not accompanied by clinical features characteristic of primary congenital glaucoma (Haab's striae, increased diameter and corneal edema) [1].

It is generally accepted that congenital glaucoma, given the sometimes quite obvious alterations that it causes in the immature child, is more easily diagnosed and better known for its higher incidence. Unfortunately, in the case of infantile and juvenile glaucoma, there are very few series studied and with a reduced number of patients, so there is usually no alternative other than to extrapolate our knowledge about the adult patient. Uncertainty increases in children with OHT due to the limited scientific evidence we have. In adults, elevated intraocular pressure is the main risk factor for developing glaucoma, and also the only one on which we can act.

A better knowledge of ocular hypertension in children is important, given the possible early damage to the optic nerve, the possible development of functional deficits in immature eyes, and since it affects a considerable percentage of the child population (3.5\%) [2]. It is unknown what proportion will reach a pathological condition that could cause the development of glaucoma. Early diagnosis and control of ocular pressure improves the prognosis in the evolution of glaucoma [3].

\section{Purpose}

To study the long-term development of a group of children with OHT, registered in our consultation, and to know their characteristics, response to treatment and possible glaucomatous damage suffered during the control period.

\section{Materials and methods}

A retrospective study, after examining the clinical records of patients from 2000 to 2015 who were studied in the Pediatric Ophthalmology units of our hospital using Perkins tonometer, Humphrey campimeter and OCT Cirrus Operator.

Inclusion Criteria: Patients between the ages of 3 and 18 who had at least on two occasions an IOP greater than $18 \mathrm{mmHg}$ and with a minimum clinical follow-up time of at least 5 years.

Exclusion Criteria: Association of other ocular pathologies, less than five years of follow-up data in their clinical history, and application of surgical treatments.

Correspondence to: Perea Pérez R, Avd/Kansas City n²8, piso 304. CP: 41007 Seville (Seville), Spain, Tel: +34 6176599 50; E-mail: rafaperea@hotmail.com

Key words: juvenile glaucoma, ocular hypertension in children, myopia Received: March 26, 2017; Accepted: April 12, 2017; Published: April 14, 2017 
Clinical-epidemiological study of the data obtained by reviewing clinical records and the complementary tests performed. The data analyses were conducted using the Stata 11 statistical program. In the statistical study and comparison of variables, we used Pearson's Chi square test and the OR Cornfield 95\% confidence limit, considering all associations as statistically significant when $p$ value $<0.05$.

\section{Results}

\section{Description of the sample}

The age range was 3 to 18 years, with a mean of 10.92 years and SD of \pm 3.77 . Fifty percent were women (21) and $50 \%$ men (21).

The distribution according to the age at diagnosis was mainly concentrated in intermediate ages, with a mode of 12 years, and a high incidence also observed between 3 and 9 years of age (34\% of the sample).

\section{Family history}

The presence of glaucoma in first and second degree relatives is significantly relevant, finding three cases of family grouping with two siblings included in the study. They represent a total of 25 patients, $58 \%$ of the study population. Of these, the transmission route is proven to be paternal in 5 cases, and maternal in 11 cases. In 10 cases (23\%) there is myopia in first and second degree relatives.

\section{Personal history}

Significantly, refractive errors were registered in 62 eyes, $83.77 \%$, with myopia being the most frequent type (41 eyes, 55\%) (Table 1).

In terms of allergic diseases, bronchial asthma was found in 6 cases and allergic rhino-conjunctivitis in 5. In this group, it is worth noting the start of treatment with corticosteroids (topical, local, or systemic) in 10 patients. Headache was reported as personal medical history in 5 patients. In two cases meningitis was referred to in childhood. There is one case with Axenfeld syndrome that was excluded from the study because it was considered a secondary glaucoma.

\section{Intraocular pressure}

Baseline IOP: The values at which it was decided to initiate ocular hypotensive treatment were recorded in our 42 patients, with a mean of $21.84 \mathrm{mmHg}$.

IOP in response to treatment: To quantify the degree of response to treatment (Figure 1). Regarding the study of both eyes separately, we found a mean IOP of $17.12 \mathrm{mmHg}, \mathrm{SD}: \pm 2.47$, in the right eye and a mean IOP of $17.24 \mathrm{mmHg}$ with SD: \pm 2.88 in the left eye.

The comparison between baseline IOP values and those of IOP in response to treatment was proven to be uniform and symmetric at the beginning, with greater dispersion and variation after treatment (Figure 2). In the analysis of baseline IOP in the right and left eyes no significant differences were found in terms of gender (being p: 0.8 and 0.9 respectively) or after treatment (p: 0.4 for the right eye and p: 0.4 for the left eye). The variation of IOP following the start of treatment is shown in Table 2 .

IOP curve: Ten of the patients underwent diurnal IOP curve with measurements taken every 2 hours, with a mean difference between morning and night of $6.25 \mathrm{mmHg}$ (Table 3).

Medical treatment used at the beginning: The $\beta$-blockers used were predominantly timolol and in 4 cases carteolol. As for

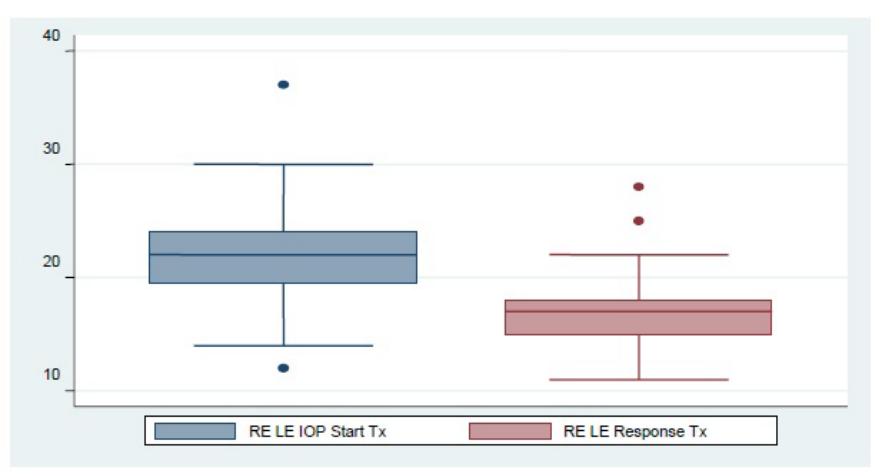

Figure 1. IOP evolution in response to treatment.

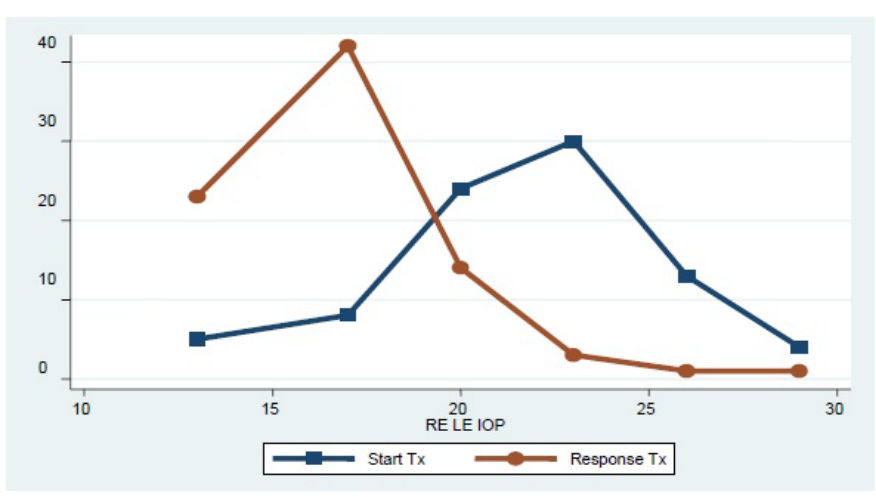

Figure 2. Distribution of IOP measurements in both eyes before and after treatment.

Table 1. Refractive errors.

\begin{tabular}{|c|c|c|}
\hline Refraction & Cases (eyes) & Overall percentage \\
\hline Emmetropia & 12 & $16.21 \%$ \\
\hline Hyperopia & 21 & $28.37 \%$ \\
\hline Myopia & 41 & $55.40 \%$ \\
\hline Total & 74 & $100 \%$ \\
\hline
\end{tabular}

Table 2. IOP variation after starting treatment.

\begin{tabular}{|c|c|c|c|c|c|}
\hline Variable & $\begin{array}{c}\text { No. of } \\
\text { samples }\end{array}$ & Mean & SD & Minimum & Maximum \\
\hline $\begin{array}{c}\text { IOP variation in absolute } \\
\text { values }\end{array}$ & 82 & 4.63 & \pm 4.13 & -5 & 22 \\
\hline $\begin{array}{c}\text { Percentage of IOP } \\
\text { variation }\end{array}$ & 82 & 19.34 & \pm 15.96 & $-25 \%$ & $59.45 \%$ \\
\hline
\end{tabular}

Table 3. Values of Diurnal IOP curve.

\begin{tabular}{|c|c|c|c|c|c|c|}
\hline Variable & $\begin{array}{c}\text { Absolute } \\
\text { Minimum } \\
\text { IOP }\end{array}$ & $\begin{array}{c}\text { Mean } \\
\text { Minimum } \\
\text { IOP }\end{array}$ & $\begin{array}{c}\text { Absolute } \\
\text { Maximum } \\
\text { IOP }\end{array}$ & $\begin{array}{c}\text { Mean } \\
\text { Maximum } \\
\text { IOP }\end{array}$ & Mean IOP & $\begin{array}{c}\text { Mean } \\
\text { Variation } \\
\text { Amplitude }\end{array}$ \\
\hline $\begin{array}{c}\text { Value } \\
(\mathrm{mmHg})\end{array}$ & 10 & 14.66 & 28 & 20.91 & 17.78 & 6.25 \\
\hline
\end{tabular}

prostaglandins (PG), the use of xalatan was predominant in 9 cases, followed by travatan in 3 cases and saflutan in only one case.

The most frequent reason for first time Ophthalmology consultation is vision loss, being 11 years old the age at which the first suspicion of OHT and/or glaucoma is usually established, and one year later when hypotensive treatment is started. Treatment with hypotensive medication has shown an adequate response (with a mean decrease of $4.7 \mathrm{mmHg}$, almost $20 \%$ of the initial value) with no cases of significant adverse effects registered. 


\section{IOP variation according to the pharmacological group used}

\section{Group treated with $\beta$-blockers}

Baseline IOP: 21.75 SD: \pm 4.14 खIOP with treatment: 17.4 SD: \pm 2.2 .

\section{Group treated with Prostaglandins}

Baseline IOP: $21.84 \mathrm{mmHg}$ SD: \pm 2.73 冈IOP with treatment: 17.77 SD: \pm 3.11 .

\section{Clinical follow-up of the patient}

11.58 years on average, with a minimum of 5 and a maximum of 25 years. The maximum and minimum IOP values with treatment were analyzed separately in each patient. The minimum IOP found presented a mean of $13.6 \mathrm{mmHg}, \mathrm{SD}: \pm 2.19$, with a range of 8 to 18 $\mathrm{mmHg}$. The maximum IOP presented a mean of $19.7 \mathrm{mmHg}, \mathrm{SD}: \pm$ 2.33 , with a range of 16 to $24 \mathrm{mmHg}$.

Cases requiring two or more hypotensive agents: In 25 cases (66.66\%), at some point, combined treatment with two or more hypotensive agents was needed to achieve normal IOP. In three cases we had to resort to the association of three drugs.

\section{Withdrawal of treatment}

In 16 cases (45.95\%) treatment was permanently withdrawn. Treatment withdrawal was mostly motivated by good IOP control. In three cases withdrawal of the treatment was decided after it was found to be inappropriate due to high pachymetry values. In only one case treatmentwasre-established aftera prolonged period without receivingit. Patients controlled after treatment withdrawal maintain a mean IOP of $14.5 \mathrm{mmHg}$, and many of them are already adults.

\section{Evaluation of the optic nerve head excavation by oph- thalmoscopy}

Optic nerve head evaluation has proven to be very useful to establish a first suspicion or alarm symptom. A pathological or asymmetric excavation of the optic nerve was described in $78 \%$ of the cases.

\section{Corneal pachymetry}

The corneal central thickness (CCT) was measured in 37 children (73 eyes) and examined by Anterior Segment optical coherence tomography (OCT). In the studied group, the mean pachymetry was $562 \mu \mathrm{m} \pm 41$. This value is higher than those obtained in other studies, although the age is also lower and the proportion of children with myopia is very high (55\%). The highest values are found in the youngest children; whereas pachymetry values decrease in the oldest groups. The 6 cases with pachymetry values greater than $600 \mu \mathrm{m}$ are children aged 10 years or younger, which is consistent with the observations by other authors (Table 4).

\section{OCT of optic nerve head}

In 36 cases OCT of the optic nerve head was performed; 23 cases (63.89\%) were found within normal limits and loss of retinal nerve fiber layers (RNFL) was detected in 13 cases $(36.11 \%)$.

Table 4. CCT measurements in both eyes.

\begin{tabular}{|c|c|c|c|c|c|}
\hline Pachymetry $(\mu \mathrm{m})$ & $\begin{array}{c}\text { No. of } \\
\text { samples }\end{array}$ & Mean & SD & Minimum & Maximum \\
\hline Right eye & 37 & 561.36 & \pm 41.499 & 450 & 660 \\
\hline Left eye & 37 & 562.00 & \pm 40.940 & 439 & 660 \\
\hline Right/Left eye & 74 & 561.68 & \pm 41.219 & & \\
\hline
\end{tabular}

\section{Campimetry}

Gold standard in the functional assessment of the patient with glaucoma. Despite the difficulty of performing this test in the pediatric patient, it was performed in 34 cases, but with limited reliability.

\section{Discussion}

In our setting, $92.8 \%$ of healthy children aged 6-14 years have an IOP below $17 \mathrm{mmHg}, 3.4 \%$ are between $17-18 \mathrm{mmHg}$, and $3.8 \%$ have an IOP greater than $18 \mathrm{mmHg}$ (outside normal limits) [2], according to the findings of Montero de Espinosa et al. [2].

Pensiero [4] described a first neonatal phase in which the mean IOP is $9.59+/-2.3 \mathrm{mmHg}$, a second phase (up to 8 years) marked by an exponential growth of IOP, which occurs earlier in males $(13.9+/$ $2.3 \mathrm{mmHg}$ ) compared to females $(14.88+/-2.39 \mathrm{mmHg})$, and a third phase of IOP stability up to 16 years, when IOP will begin matching normal adult values. No significant differences are found between both sexes. They conclude that normal IOP in infancy is always lower than $17 \mathrm{mmHg}$, lower than in adult age, and more significantly in the neonatal period and up to 4 years of age [4].

A more recent study, with very similar results, describes as an interesting finding that IOP correlated directly with central corneal thickness and refraction, and inversely with the anteroposterior axis of the eye [5-7]. OCT has high reproducibility, and good correlation with ultrasonic pachymetry $[8,9]$. Ehlers's approach showed that, at a true IOP of $20 \mathrm{mmHg}$, measured by anterior chamber cannulation, a corneal thickness of $450 \mu \mathrm{m}$ would produce an underestimation of 5.2 $\mathrm{mmHg}$ in the applanation tonometry and a corneal thickness of 590 $\mu \mathrm{m}$, an overestimation of $4.7 \mathrm{mmHg}$ [8-10]. We believe that corneal thickness plays an important role in the actual determination of IOP measured by applanation tonometry.

Published studies are limited but show an average pachymetry of $537 \mu \mathrm{m} \pm 33$ in the healthy newborn, with a thinner value reported in the premature child. Between the second and third year of life, a thickness is reached with values very similar to those of the adult, with little variability with respect to age since then [7]. Other studies find that it is at 10 years of age when it begins to be compared to adult thickness [11]. These same studies have found racial differences, reporting a thinner cornea in Chinese and African American children. In healthy children with a moderately elevated IOP, and without other signs of glaucoma, a more conservative assessment can be performed if their central corneal thickness (CCT) is greater than normal for their age. In contrast, in children with a moderately elevated IOP and a CCT lower than normal for their age, it is necessary to control more often the possible appearance of signs of glaucoma.

The increase in CCT with age in children with ametropias [8], is a very interesting finding, since it may partly justify the largest number of children under 10 years of age with higher than normal tonometry values. There is a high proportion of children with OHT (40\%) who tend to normalize their ocular pressure with age, (19.81 years \pm 6.43$)$, after years of needing treatment to keep it within normal values. This makes us think that some of the children who are still under treatment, as they grow, will reach normal IOP values without treatment. Therefore, the proportion of children in whom OHT disappears spontaneously could become more than half of the group studied. The reason for this positive evolution in almost half of the children with OHT is unknown. It may be due to the maturation of the aqueous humor drainage structures during development, which we have not been able to verify, since the irido-corneal angle examination with biomicroscopy or anterior pole OCT has not been performed systematically. 


\section{Conclusions}

-Forty percent of children with OHT tend to normalize their ocular pressure with age, occurring at a mean age of 19.81 years $( \pm$ 6.43).

-The response to medical treatment has been in all cases sufficient, with prostaglandins being currently the treatment of choice.

-The most frequent family history was glaucoma (58\%) and myopia (23\%).

-The most frequent systemic pathological history was of airways disease, associated with the use of corticosteroids in many cases.

-The most frequent refractive condition was myopia (55\%).

-In the literature review, we did not find any series of children with OHT as extensive or over such a long period of time.

\section{References}

1. Mendez-Hernandez C, Arcos-Villegas G, Garcia-Sanchez J, Garcia-Feijoo J (2015) Clinical classification and medical treatment options in childhood glaucoma. Arch Soc Esp Oftalmol 90: 557-561. [Crossref]

2. Montero de Espinosa, Contrera MI, Torralba CJ (1997) Presión intraocular en la infancia. Su relación con la miopía. Arch Soc Esp Oftalmol72: 855-860.
3. Muñoz-Negrete FJ, Pérez-López M, Won Kim HR, Rebolleda G (2009) [New developments in glaucoma medical treatment]. Arch Soc Esp Oftalmol 84: 491-500. [Crossref]

4. Stefano P, Pozzo D, Paolo P (1992) Normal Intraocular Pressure in Children. J Pediatr Ophthalmol Strabismus29: 79-84.

5. Sihota R, Tuli D, Dada T, Gupta V, Sachdeva MM (2006) Distribution and determinants of intraocular pressure in a normal pediatric population. $J$ Pediatr Ophthalmol Strabismus 43: 14-18. [Crossref]

6. Mohamed S, Lee GK, Rao SK, Wong AL, Cheng AC, et al. (2007) Repeatability and reproducibility of pachymetric mapping with Visante anterior segment- optical coherence tomography. Invest Ophthalmol Vis Sci48: 5499-5504. [Crossref]

7. Li Y, Shekhar R, Huang D (2006) Corneal pachymetry mapping with high speed optical coherence tomography. Ophthalmology113:792-799. [Crossref]

8. Hussein MA, Paysse EA, Bell NP, Coats DK, Brady McCreery KM, et al. (2004) Corneal thickness in children. Am J Ophthalmol 138: 744-748. [Crossref]

9. Haider KM, Mickler C, Oliver D, Moya FJ, Cruz OA, et al. (2008) Age and racial variation in central corneal thickness of preschool and school-aged children. J Pediatr Ophthalmol Strabismus 45: 227-233. [Crossref]

10. Bueno-Gimeno I, Gene-Sampedro A, Morales-Hernández MC (2013) Influencia del error refractivo en la presión intraocular y en el espesor corneal central en una población de 6 a 17 años. Gaceta de optometría y óptica oftálmica1-8.

11. European Glaucoma Prevention Study (EGPS) Group, Miglior S, Pfeiffer N, Torri V, Zeyen T, et al. (2007) Predictive factors for open-angle glaucoma among patients with ocular hypertension in the European Glaucoma Prevention Study. Ophthalmology114: 3-9. [Crossref]

Copyright: (C2017 Espinosa MMD. This is an open-access article distributed under the terms of the Creative Commons Attribution License, which permits unrestricted use, distribution, and reproduction in any medium, provided the original author and source are credited. 